\title{
Research and assessment of competitiveness of large engineering complexes
}

\author{
V.V. Krivorotov ${ }^{1, *}$, A.V. Kalina ${ }^{1}$, and V.D. Tretyakov ${ }^{2}$ \\ ${ }^{1}$ Department of Economics of Industrial and Energy Systems, Ural Federal University named after the first President of Russia B.N. \\ Yeltsin, Ekaterinburg, Russia \\ ${ }^{2}$ Project Office, CJSC "Energomash (Ekaterinburg) - Uralelectrotyazhmash”, Ekaterinburg, Russia
}

\begin{abstract}
The urgency of the problem of ensuring the competitiveness of manufacturing and high-tech sectors is shown. Substantiated the decisive role of the large industrial complexes in the formation of the results of the national economy; the author's interpretation of the concept of "industrial complex" with regard to current economic systems. Current approaches to assessing the competitiveness of enterprises and industrial complexes are analyzed; showing their main advantages and disadvantages. Provides scientificmethodological approach to the study and management of competitiveness of a large industrial complex; the description of its main units is provided. As a Central element of the scientific methodology approach proposed the methodology for assessing the competitiveness of a large industrial complex based on the Pattern-method; a modular system of indicators of competitiveness is developed and its adaptation to a large engineering complexes is made. Using the developed methodology the competitiveness of one of the largest engineering complexes of the group of companies Uralelectrotyazhmash, which is the leading enterprises in electrotechnical industry of Russia is assessed. The evaluation identified the main problems and bottlenecks in the development of these enterprises, and their comparison with leading competitors is provided. According to the results of the study the main conclusions and recommendations are formed.
\end{abstract}

\section{Introduction}

The modern world is characterized by a high level of economic activity in its different manifestations and various dynamic changes that affect socio-economic development of the society. In such conditions, competition is the main driving force of development of economic entities. As a consequence, the problem of increase of competitiveness of economic entities, from private companies to the largest transnational companies (TNCs) and states' economies as a whole is of high scientific and practical significance in the modern dynamically changing world. Research in this direction is presented by numerous works by leading scholars and practitioners. These studies develop a variety of approaches to providing, enhancing and managing the competitiveness of economic entities, which strongly differ in the basic principles and ideology of the research, and from positions of the methods and models. However, despite the diversity of ongoing research, the vast majority of them relie on a scientific approach involving primary research dealing with problems of competitiveness, and then practical implementation of the scientific principles in the activities of economic entities. Such positions are followed by a group of authors in solving the problems and challenges identified in this article.

\section{The urgency of the problem of competitiveness of machinery industries in modern Russia}

Dynamics of world economic development shows that in fact since the nineteenth century the basis of all the changes, transformations, became the scientific-technical progress (STP). First of all, STP is associated with the interconnected development of science and technology, using in production advanced achievements in science and invention, leadership in innovation activity, etc. Thanks to the active manifestation of STP many countries not rich in natural and material resources, have achieved tremendous success, becoming world leaders in certain areas and segments of activity and achieving high performance levels and the quality of life for their inhabitants.

As the experience of the development of the leading economies in the world shows, the basis of STP are the so-called high-tech industries which are primarily associated with the manufacturing sector of the economy, but mainly with such segment as machinery production. Namely, in the engineering sector there are the most high-tech and science-intensive products with the highest degree of readiness and the highest demand in the markets of finished products.

Consequently, we can say that the status of engineering industries largely determines the 
competitiveness and development prospects of the state economy as a whole. Therefore, the task of maintaining and enhancing the competitiveness of engineering industries and their individual segments becomes a priority associated with the current and prospective development of the economies of individual countries and regions. The basis for its solution is the development and implementation of competitive strategies of development of machinery enterprises that ensure their work at a level appropriate to leading world analogs from the standpoint of competitiveness. Thus, the formation of competitive strategies should be based on the approach, seamlessly taking into account the different sides and aspects that determine the competitiveness of enterprises in their continuous comparison with the characteristics of the external environment (competitors). Another key aspect of the modern development of the world economy is globalization processes, accompanied by the gradual formation of a common economic space, "erasing" of borders and barriers in foreign relations between states, the formation of TNCs, the scale of which is comparable to the economies of individual countries. As a result, today the central object of activity of economic systems becomes industrial complex (IC) associated with large integrated structures, which are the main drivers of the development of socio-economic systems. In this paper the authors give the following interpretation of the concept of IC: "the industrial complex is an integrated structure consisting of the main enterprises of the production cycle, integrated into a single technological chain of production, from development, production to sales and after-sales service, and auxiliary and service enterprises, collaborating and benefiting from it in the form of a synergistic effect" [1, p. 76].

Experience shows that the use of approaches to assessing and ensuring the competitiveness of individual companies does not allow to consider all features and functions of IC. The problem is that in the industrial complex, the enterprises have close links within the production cycle, from ore extraction and raw materials to its processing, the manufacture of final products and delivery to consumer, and these connections form a certain synergy, which, in fact, increases the competitiveness of these structures compared with private enterprises. Thus, it is necessary to develop new scientific and methodological approach to the assessment and management of competitiveness of major IC, which form the modern economic landscape of the world economy. This approach will allow to assess the current IC's position on the background of leading competitors, identify the main "point of application" of control actions in order to increase competitiveness and to form an optimal portfolio of activities required in the context of resource constraints.

One of the main components of this approach should be a comprehensive method of assessing the competitiveness of the IC, allowing on the one hand to carry out its current rating in comparison with the main competitors and to identify bottlenecks and "strengths" of the considered IC. On the other hand, this technique and the obtained results should be the basis for development of competitive strategies of the IC and its constituent companies.

\section{The analysis of modern approaches to evaluation of competitiveness of economic entities}

As shown above, competition is the main driving force of development in market models. As a result, the approaches to assessing the competitiveness of various actors of the current socio-economic systems have been widely developed: from small companies to national economies and transnational corporations.

The founders of papers on the study of competition and competitiveness are the representatives of classical political economy - A. Smith and D. Riccardo [2, 3] with their perfect competition models, which were ahead of their time. So, A. Smith identified competition as the main driving force of the optimization of parameters "price-quality" of products in order to capture and retain competitive advantage.

In the future, as the development and complexity of socio-economic systems and processes there were other, more complex and sophisticated models of competition. Primarily, these include:

1. The structural approach developed in the work of A. Cournot [4], F. Edgeworth [5], J. Robinson [6], E. Chamberlin [7] and many other famous scientists. In this approach when investigating competition the emphasis is shifting from rivalry firms with each other on the analysis of market structure, that is, those conditions in which firms exist.

2. The functional approach proposed by J. Schumpeter in the early 20th century, who considered competition as the rivalry of old and new [8]. Further, this approach has been developed in the works of many known scientists. For instance, F. Hayek interpreted the competition as a discovery procedure, in accordance with which as the main criteria of competitiveness of the company performs the innovative activity [9].

3. The marketing approach based on the idea of consumption control, which, in turn, involves the environment and, in particular, consumers manipulation by the producers and distributors. Among the scientists adhering to this approach, highlight J. Galbraith [10], F. Kotler [11] L. L. Radder and Lowe [12] and many others.

Along with the development of approaches to the study of competition the approaches and methods for assessing the competitiveness of managing subjects have been broadly developed. Speaking on the assessment of the competitiveness of enterprises and IC in the first place, should be highlighted the approaches and methods that take into account the competitiveness of the products. In most methods based on a specific approach, the evaluation of the goods is proposed to be carried out by the use of economic and qualitative indices of competitiveness of goods, which characterize, respectively, the cost and technical (qualitative) characteristics of the investigated products [13 - 14 and others]. Not less popular are the methods based 
on the competitive strategy of mainstreaming the company's position in the market, attractiveness of the industry, but also based on strategic behavioral recommendations. In this group of methods should allocate the Boston consulting group matrix "relative market share / market growth Rate" [15], Mc Kinsey matrix "Position / attractiveness of the industry" [16], M. Porter's "Strategic goal / Strategic advantage" matrix [17].

In the methods based on the concept of the value chain of the company, the latter's activity is divided into primary, associated with the production and distribution of the product, and secondary, related to support activities that provide inputs and infrastructure, which allow to perform primary activities. The competitiveness of enterprise is considered from the perspective of efficient implementation of the above activities relative to its competitors [18].

Widespread in practice became methods based on the business valuation. The basic idea of these methods is that the higher the value of the enterprise, the more economic benefit it can bring to its owner and consequently, the higher is its level of competitiveness [19-22 and others].

In recent times widespread for the tasks associated with the assessment of the competitiveness of enterprises and IC have become methods based on game theory. The essence of this group of methods lies in the choice of optimal strategy of behavior of economic entities aimed at obtaining maximum gains or reduce losses in competition with other players. As the optimized criterion can be the performance of the entity: bank branches' expenditures [23], market positioning [24, 25], the production price [26] and other indicators.

In addition to these methods, in the literature one can find links to other less common groups of methods (graph-analytical methods, potential methods, integrated methods, etc.). However, in most cases they use approaches and techniques that are an integral part of the above mentioned methods.

Summing up the analysis of methods and approaches to assessing the competitiveness of enterprises and IC, it can be noted that in the vast majority of research and evaluation of the competitiveness of enterprises and IC focuses on one of the groups of factors determining competitiveness (product, marketing, management, etc.). On the other hand, there are almost no approaches based on comprehensive consideration of various influencing factors. Existing methods of estimation of competitiveness of business entities do not take into account the complex factors of competitiveness inherent to the big IC. In this regard, the apparent urgency of developing a comprehensive methodological approach to assessing the competitiveness of major IC, comprehensively taking into account various aspects of their activities and organization is obvious.

\section{Scientific and methodical approach to the assessment and management of competitiveness of large industrial complexes}

In the developed approach IC, as noted earlier, is considered as an integrated production structure united around the technological chain of production, sales and after-sales service of products, which may include a sufficiently large number of enterprises (in some cases several dozen or more).

The proposed approach is a systemic approach, according to which the object is seen as a holistic set of elements in the set of relations and links between them [27]. In this case, there are three major interrelated units aimed at sequential solution of the problem of the assessment and management of competitiveness of the IC:

1. The Section of evaluation of the current level of competitiveness of the IC on various aspects of financial and economic activity.

2. The Section of selection of the optimal portfolio of control actions aimed at improving the competitiveness of the IC.

3. The Section of the formation of predictive strategies for the development of ICs aimed at ensuring the competitiveness of long-term competitive advantage of ICs in the forecast period.

The main tasks in the first section, are complex factorial assessment of competitiveness of the studied ICs with the identification of strengths and bottlenecks in their development and definition (based on evaluation) the main directions of development of the IC in the foreseeable future, as well as "points of application" of control actions.

The second section solves the problem of selecting the optimal portfolio of control actions in order to maximize the increment of the competitiveness of the ICs in terms of existing resource constraints.

Finally, the task of the third section is elaborating and implementing the strategy for the development of ICs in the forecast period (through the various stages of the prospective period), which would allow to ensure the survival and maintenance of sufficient levels of competitiveness of the IC and its constituent businesunits in the future.

A central element of the considered scientific and methodical approach, linking and "coordinating" the work of all of the above section is a technique of a complex estimation of competitiveness of the IC.

Methods of assessing the competitiveness of the IC is based on the Pattern-method widely used to solve such problems [28], which has been successfully applied by the authors before $[1,27$, etc.]. In accordance with the proposed approach the methodology involves the following main provisions and principles of the assessment of the competitiveness of the IC:

- comparison of indicators of competitiveness of the investigated IC with some standard (base) model with predetermined characteristics; 
- integrated indicator of competitiveness as the ultimate goal of the assessment calculations and comparisons; - the block structure of competitiveness indicators of IC.

As shown above, the ultimate aim of assessing the level of competitiveness of the IC in accordance with the methodology is the determination of the integral competitiveness index that combines various sides and aspects of IC's operations. In this case, the realized and potential competitive capabilities of the IC are estimated. The composite index of competitiveness is calculated by two major characteristics:

$$
C_{I C}=\sqrt{C_{c u r} \cdot C_{p o t}},
$$

where $C_{c u r}$ is the level of IC's current (implemented) competitiveness; $C_{p o t}$ is the IC's competitive potential.

Among the main advantages of the presented approach can be identified:

- the possibility of quantitative measurement of the competitiveness index that allows you to compare multiple ICs or multiple variants of development of the same IC;

- a comprehensive consideration of various criteria for the development of the IC without giving priority to some chosen criterion;

- the methodology is "open" and allows relatively easily to change the composition of indicators, $C_{c u r}$ and $C_{p o t}$ depending on your goals, the characteristics of individual ICs and industries, as well as available software;

- in the equation (1) it is possible to combine the results of evaluations of individual aspects of an IC, made on the basis of various methodical approaches and algorithms.

Each of the characteristics presented in the equation (1) is broken into smaller components - blocks that characterize certain aspects of IC's operation (production, marketing, corporate culture, etc.). In turn, each block consists of individual indicators of competitiveness $-C i(5-7$ or more indices in the block), the ultimate characteristics of competitiveness of the investigated ICs in comparison with the main competitors or key characteristics of the competitive environment.

Calculating the $C i$ is the mapping of the relevant indicator of the competitiveness of the IC with the same index of the base model:

$$
C_{i}=\frac{I_{i}}{I_{\text {basis }, i}},
$$

where $I_{i}$ is the value of indicator $i$ of IC's competitiveness, $I_{\text {basis }, i}-$ the basic valueof $i$ competitiveness indicator.

Indicator of current competitiveness,

$C_{c u r}$ is tinguishes the following components (blocks):

1) the operating efficiency and market position $\left(C_{I C l}\right)$

2 ) the competitiveness of IC's key products $\left(C_{I C 2}\right)$

3 ) the condition and efficiency of functioning of IC's industrial-technological base $\left(C_{I C 3}\right)$

4) the efficiency of staff and personnel policy $\left(C_{I C 4}\right)$
5) the quality of IC's organization and management $\left(C_{I C 5}\right)$

6) investment and innovation activity of IC $\left(C_{I C 6}\right)$

7) risks associated with the activity of IC $\left(C_{I C 7}\right)$

Indicator of the IC's competitive potential $\left(C_{p o t}\right)$ is broken down to such components (blocks):

1) the potential use of manufacturing capacity $\left(P_{m c}\right)$

$2)$ the market potential of the IC $\left(P_{\text {market }}\right)$

3) accordance of IC's personnel qualification to demands of scientific and technical progress $\left(P_{\text {pers }}\right)$

A key feature of the scorecard methodology is the orientation to available sources of information (enterprises' data reporting, public information data on competitors, raw materials and product markets, statistical services, etc.). This distinguishes the proposed method of assessing the competitiveness of ICs from many of the same techniques where the evaluation rely heavily on the expert assessment procedure and survey data, the implementation of which in many cases is difficult.

\section{Assessment of competitiveness of engineering complexes on the example of a group of companies uralelectrotyazhmash}

The proposed scientific and methodical approach was implemented in assessing the competitiveness of one of the largest Russian engineering complex, formed by a group of companies JSC "Energomash (Ekaterinburg)Uralelectrotyazhmash" and LLC "Elmash (UETM)", which are the leading enterprises of electrotechnical industry of Russia. The received results became a basis for formation of competitive strategies of development of these enterprises.

In evaluating competitive environment for the group of companies Uralelectrotyazhmash the world's leading manufacturers of electrical equipment were consideredSiemens (Germany), ABB (Sweden), Alstom (France), Hyundai Heavy Industries (South Korea), Toshiba (Japan), as well as a number of Russian manufacturers working in this area -JSC "Elektrozavod", LLC "Togliatti transformer", "CJSC "SverdlovElectro" Group, "Power machines - Toshiba. High voltage transformers", the company "High-Voltage Union", CJSC "Elektroapparat". In the formation of basic values for individual indicators of competitiveness, which is necessary for carrying out comparative analysis in accordance with the Pattern method, in most cases, the values by corporations Siemens, $\mathrm{ABB}$, Alstom, is the world's leading manufacturers in the world were taken.

Competitiveness assessment was conducted in the period $2012-2015$, the results of the calculations are presented on Figure 1. The assessment at this stage due to the information restrictions and high uncertainty of the current situation of the world and Russia was carried out only in terms of the level of current (implemented) competitiveness of the IC $\left(C_{\text {cur }}\right)$ and constituent components, which, in fact formed integral index of competitiveness $-C_{I C}$. In addition, in the calculations for 
the same reasons, was not considered an indicator of risks associated with the activity of IC $\left(C_{I C 7}\right)$.

As shown by the assessment, the unit 1 "Operational efficiency and market position" in the group of UETM demonstrated a failure in 2014, while overall long-term trend towards a slight decrease in the level of competitiveness. This is due primarily to lower net income of UETM caused by falling order volumes because of the reduction of investment programs of key customers with a high level of fixed costs. Nevertheless, the indicator of operational efficiency of UETM surpassed the analogue competitor Alstom Grid.

On the block 2 calculations were carried out in an express assessment on the main tyoes of high voltage equipment: live-tank circuit breakers VGT-UETM 126 $\mathrm{kV}$ dead-tank circuit breakers VEB-UETM $245 \mathrm{kV}$ (compared with analogues produced by Siemens), as well as gas-insulated switchgear KRUE-UETM on 126 $\mathrm{kV}$ (compared with the analogous $\mathrm{ABB}$ for weight and size indicators). Overall, it can be stated that the products manufactured by UETM correspond to the world standards in technical performance and quality indicators.

Block 3 "Condition and efficiency of functioning of industrial-technological base" assessment shows relatively low values of indexes of competitiveness. The level of depreciation of group UETM exceeds the similar indicator of the leading competitors. Approximately similar results shows an energy intinsity indicator.

The most problematic position of the group companies of UETM is the level of the investment activity (block 6).

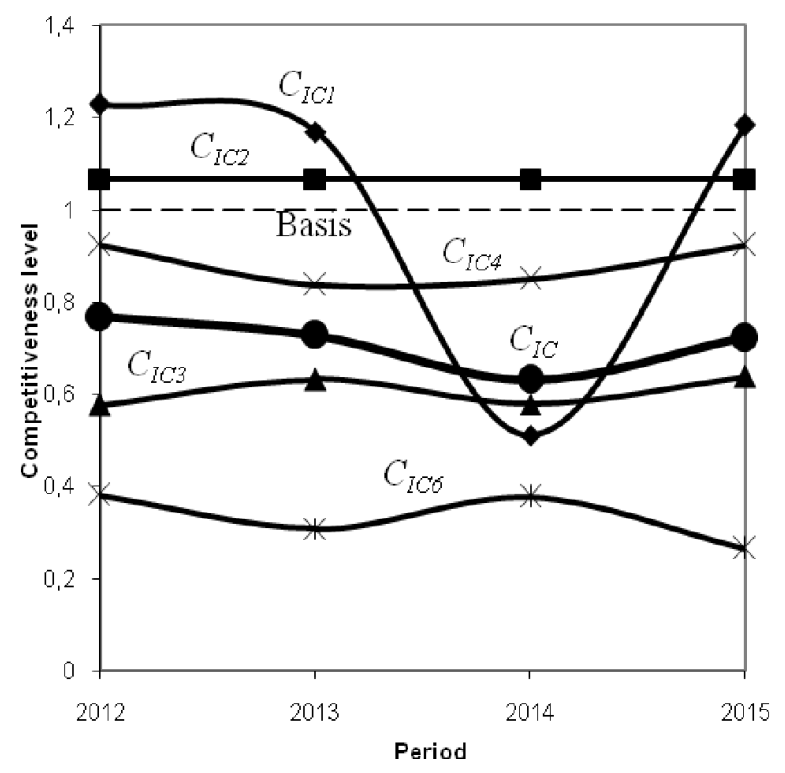

Fig. 1. Assessment of competitiveness of the group of companies Uralelectrotyazhmash compared to leading competitors.

First of all, with high innovation activity and R\&D expenses there were practically no investments in updating production facilities.
Overall, the value of the integral index of competitiveness of UETM from 2012 to 2014 has been steadily reducing, which is caused primarily by shortage of working capital funds to finance orders and gain profit as well as investing in upgrading the production basis. However, at the end of the period (2015) there has been a fracture of the negative tendency, and the integral index of competitiveness began to return to the state of 2013. The evaluation found that when implementing investment projects aimed at improving the competitiveness of the group UETM, the target is to give preference to those which focus on:

1) development of new market niches and attracting new orders for the purpose of working capital replenishment.

2) renewal of fixed assets due to the adoption of energy efficient technologies as well as technology excluding the residual material suppliers with an effective increment of the proportion of value added by an enterprise in the manufacture of its products;

3) upgrade infrastructure to increase the energy efficiency.

Direct selection of investment projects within identified priority areas should be conducted using the model of optimal portfolio selection of control actions according to the criterion of the maximum increment of the competitiveness in conditions of limited resources. In detail, the algorithm for constructing the model and conducting the selection procedure is considered in [27].

\section{Conclusion}

The study and the results obtained allow to note the following:

1. Based on the analysis of modern approaches to the study of competition and competitiveness of economic entities a scientific and methodical approach to the assessment and management of competitiveness of large industrial complexes, which are the central elements of economic activity in modern economies is developed. The proposed approach relies on the use of methods of system approach and system analysis and takes into account the relationship between the state of the IC and control actions oriented to change of this state towards meeting a set of requirements from the standpoint of competitiveness.

2. A comprehensive method of assessing the competitiveness of the IC that has the property of universality and is applicable to ICs, which operate in various industries, and based on the method of Pattern is developed. In accordance with the methodology, assessment of competitiveness level is carried out by the comparison of the investigated IC with some basic model that characterizes the similar figures of the leading competitors or the competitive environment in general. The ultimate goal of the evaluation of the developed method is the determination of the combined (integral) index of competitiveness, which is calculated on the base of the aggregate competitiveness indicators describing different aspects of development and functioning of the IC. 
3. Practical implementation of the developed methodological tools applied to the problem of evaluation of the competitiveness of IC group UETM, which is the largest engineering complex in Russia is carried out. The results of the assessment revealed strengths and weaknesses of the activities of UETM in comparison with leading competitors, factorial causal analysis is conducted. The obtained results allow to begin closely to develop a roadmap for the development of the IC and to define the main strategic orientations of this development.

This research was supported by the Government of the Russian Federation (Act 211, agreement № 02.A03.21.0006).

\section{References}

1. V.V. Krivorotov, A.V. Kalina, V.D. Tretyakov, S.E. Erypalov, The Competitiveness of Socio-Economic Systems: Challenges of the New Era, 75-138 (2014)

2. A. Smith, Inquiry into the Nature and Causes of the Wealth of Nations (Petrocom, Petrozavodsk, 1993)

3. I.A. Stolyarov, Anthology of economic classics (Econav-Key, Moscow, 1993)

4. A. Cournot, Recherches sur les principes mathematiques de la theorie des ri-chesses (Paris, 1838)

5. F.Y. Edgeworth, Mathematical Physics: An essay on application of mathematics to the moral sciences (1881)

6. J. Robinson, The Economics of Imperfect Competition (Progress, Moscow, 1986)

7. E. Chamberlin, The Theory of Monopolistic Competition: A Re-orientation of the Theory of Value (Ekonomika, Moscow, 1996)

8. J. Schumpeter, Theory of Economic Development (Progress, Moscow, 1982)

9. F. Hayek, The Road to Serfdom (Ekonomika, Moscow, 1992)

10. J. Galbraith, The new industrial society (Progress, Moscow, 1969)

11. F. Kotler, Marketing management. Express course (Piter, Saint Petersburg, 2003)

12. L. Radder, L. Louw, Long Range Planning, 31, 4, 549-559 (1998)

13. L.N. Chaynikova, V.N. Chaynikov, Competitiveness of the Product (Tambov State Technical University, Tambov, 2007)
14. R.A. Fatkhutdinov, Strategic Marketing (IntelSintez Business School, Moscow, 2000)

15. B. Henderson, The Product Portfolio. https://www.bcgperspectives.com/content/Classics/s trategy_the_product_portfolio/.

16. McKinsey \& Company, Enduring Ideas: The GEMcKinsey nine-box matrix (2008). http://www.mckinsey.com/insights/strategy/endurin g_ideas_the_ge_and_mckinsey_nine-box_matrix.

17. M.E. Porter, Competitive Strategy: Techniques for Analyzing Industries and Competitors (Alpina Business Books, Moscow, 2005)

18. M.E. Porter, On Competition, updated and expanded edition (LLC "ID Williams", Moscow, 2010)

19. T. Copeland, T. Koller, J. Murrin, Valuation: Measuring and Managing the Value of Companies (Olymp-Business, Moscow, 2005)

20. M. Scott, Value Drivers. The Manager's Framework for Identifying the Drivers of Corporate Value Creation (Olymp-Business, Moscow, 2005)

21. T.A. Khudyakova, A.V. Shmidt, Proc. of The 26th International Business Information Management Association Conference, 1607-1611 (2015)

22. T.A. Khudyakova, A.V. Shmidt, Mediterranean Journal of Social Sciences, 6, 4, 274-279 (2015)

23. V. Cerasi, B. Chizzolini, M. Ivaldi, Applied Economics, 34, 2213-2225 (2002)

24. B. Doberman, H. Gatingnon, G. Sargsyan, Using Attraction Models for Competitive Optimization: Pitfalls to avoid and Conditions to Check, INSEAD Working Papers, 2006/27/MKT.

25. V. Kadiyali, K. Sudhir, R. Vithala, Methods in Marketing. International Journal of Research in Marketing, 18, 161-186 (2001)

26. S. Sriram, V. Kadiyali, Johnson School Research Paper Series, 14-07 (2007)

27. V.V. Krivorotov, A.V. Kalina, T.V. Matveeva, A.Yu Bayranchin, Improving the Competitiveness of the modern Russian Territorial-Industrial Complexes (Urfu, Ekaterinburg, 2013)

28. Pattern, from Wikipedia, the free encyclopedia. https://ru.wikipedia.org/wiki/\%D0\%9F\%D0\%B0\% D1\%82\%D1\%82\%D0\%B5\%D1\%80\%D0\%BD.

29. V.D. Tretyakov, V.V. Krivorotov, A.V. Kalina, Bulletin of Ural Federal University. Series Economics and Management, 5, 140-149 (2013) 